\title{
Application of Psycho-Social Management in Generalized Anxiety Disorder: A Clinical Case Perspective
}

\author{
Shilpi Aggarwal ${ }^{1}$, Prashant Srivastava ${ }^{2} *$
}

\section{ABSTRACT}

Objectives: The present study aims to explore the course of generalized anxiety disorder and to assess the application of psycho-social management in alleviating the symptoms associated with generalized anxiety disorder and to improve the client's overall functioning. Research design: Case study. Sample and method: This study was carried out in Hyderabad and 33 years old married male was included. Treatment plan was formulated according to psycho-social management wherein different management techniques were utilised to modify the client's generalized anxiety beliefs and the associated behaviours. Result: Findings of the assessment showed significant distress and impairment in overall functioning. Stressor activates his dysfunctional belief which shifts his attention to minor perceptual disturbance and results in misinterpretation of these trivial variations. Psycho-social management techniques successfully restructured his dysfunctional beliefs and remarkably improved his functioning. Conclusion: On the basis of results, it can be ascertained that psycho-social management is an effective approach to treat generalized anxiety disorder.

Keywords: Psycho-Social Management, Generalized Anxiety Disorder, Clinical Case

Generalized anxiety disorder has been called the "basic" anxiety disorder, in the sense that generalized anxiety is, by definition, a component of other anxiety disorders. But only recently have we begun to delve into the nature of generalized anxiety disorder. Only recently have we begun to evaluate effective psychological treatments for this problem, and only in the past several years has evidence begun to appear that we can in fact treat this problem successfully. This is no small feat, since generalized anxiety disorder, although characterized by marked fluctuations, is chronic.

\footnotetext{
${ }^{1}$ Clinical Psychologist, Child Development Centre, Department of Paediatrics, Maulana Azad Medical College and associated LokNayak Hospital, New Delhi, India

${ }^{2}$ Psychiatric Social Worker, Child Development Centre, Department of Paediatrics, Maulana Azad Medical College and associated LokNayak Hospital and PhD Scholar, Department of Social Work, JamiaMilliaIslamia, New Delhi, India

*Responding Author
}

Received: January 6, 2017; Revision Received: January 22, 2017; Accepted: February 2, 2017

(C) 2017 Aggarwal S, Srivastava P; licensee IJIP. This is an Open Access Research distributed under the terms of the Creative Commons Attribution License (www.creativecommons.org/licenses/by/2.0), which permits unrestricted use, distribution, and reproduction in any Medium, provided the original work is properly cited. 
Generalized anxiety disorder (GAD) is a highly prevalent, chronic, costly and disabling mental disorder (Tyrer \& Baldwin, 2006). It is characterized by excessive and persistent worry and anxiety about everyday internal and external events, in combination with various psychological and somatic complaints, such as autonomic arousal, restlessness, fatigue, problems with concentrating, irritability, and sleep problems (American Psychiatric Association, 1994). Because most patients are still affected after 6 to 12 years, GAD is usually considered to be a chronic disorder (Yonkers, Dyck, Warshaw, \& Keller, 2000). The 12-month prevalence rate of GAD has been estimated to be between 1.2 and $1.9 \%$ and the lifetime prevalence between 4.3 and 5.9\% (Tyrer \& Baldwin, 2006).

Some have even considered that generalized anxiety disorder might be better conceptualized as a personality disorder, since many individuals with this problem cannot report a definitive age of onset; rather, they note that it has been with them all their lives.

Generalised anxiety disorder (GAD) is one of the most common anxiety disorders seen in primary care (Ciechanowski \& Katon, 2009). It is characterised by excessive and inappropriate worrying that causes significant distress or impairment. Recovery from GAD can be less likely than recovery from major depression.

Approximately 35 to $50 \%$ of people with major depression also meet the criteria for GAD (Ciechanowski \& Katon, 2009). When there is a diagnosis of both depression and anxiety, or if depression follows an anxiety disorder, this usually indicates a more severe anxiety disorder with a poorer prognosis. If anxiety symptoms arise as a consequence of depression, effective treatment of the depression will often relieve the anxiety symptoms (Baldwin et. al. 2005).

\section{A Case Report:}

Mr. R, 33 years, male, married, Hindu, educated up to B.A, hailing from Lower Middle Class from army personnel came with the chief complaints of Tension, Head ache, Shivering of hands, Dry mouth, Increase heart rate, Loss of appetite, Lack of concentration in daily work, Keep forgetting small things, Easily gets irritated, Doubts his mental ability, Confusion in taking decisions, Restless and fatigability The client was asymptomatic and his symptoms started with the symptom like headache and tension that is whenever he is working or free on during day time mostly. He is unable to concentrate on his work and his studies as he keeps on doubting his mental ability (especially in studies). At times when he has to take a decision or when he has a big responsibility at hand then he experiences dryness of mouth, increased heart rate and shivering of hands. He tends to take a lot of time in doing performing an activity nowadays as he easily forgets the instructions of his army personnel. He tends to forget the directions and the places. He seems to be very confused nowadays to the extent that he is not able to take simple decisions of his daily life by his own. As a result of forgetting and lack of concentration he easily gets irritated. 
$\mathrm{Mr} \mathrm{R}$ is the $3^{\text {rd }}$ issue of consanguineous parents. There are no complications reported in the birth and development. All the developmental milestones were reported to be normal; there is no history of childhood disorders as reported by the client. Mr. R's father's age is 65 years, he is a farmer and mother's age of 60 years, she is a house wife. His elder brother and younger brother age is 41 and 37 respectively and relationship with his brothers is not cordial.

On MSE, Mr. R was neatly dressed and well kempt, maintained eye contact. He was fully conscious and alert and was in touch with his surroundings. Rapport was established easily. She is oriented to person, place and time. Her psychomotor activities were within normal limits; her speech was relevant and coherent and goal directed. On affect subjectively she reported being sad and objectively depressed. On thought content excessive preoccupation was present. Attention could be aroused and could be sustained for required period of time. Her memory was intact. Overall intelligence was found to be average. Her test judgment was intact and her personal and social judgment was impaired Insight was present at level II.

\section{REASON FOR TAKING FOR INTERVENTION}

To reduce intense fear and anxiety, autonomic symptoms, unable to perform in army, negative cognition, Low self- confidence and to give awareness regarding the manifestations of generalized anxiety disorder.

\section{SPECIFIC AREAS TO BE FOCUSED}

\section{Short- term objectives}

- $\quad$ Decrease the autonomic arousal while in social situations

- $\quad$ Decrease anxiety associated with performing well on a given task

\section{Long- term objectives}

- $\quad$ Improve coping strategies

- $\quad$ Developing problem solving skills

- $\quad$ Improve self confidence

\section{TYPES AND TECHNIQUES OF INTERVENTION}

\section{Psycho-education}

The main purpose of psycho-education was to give awareness about the nature and cause of her illness. It is mainly aimed at educating her that how her symptoms were started, what were the triggering factors, and how it was maintained.

\section{Relaxation training}

The relaxation technique is widely used strategies to manage and reduce pain and stress. Among various stress management approaches, relaxation procedures have provided strong empirical support for bringing about positive physiological, psychological and emotional changes. The progressive relaxation is one of the most popular and widely used forms of relaxation. The major

(C) The International Journal of Indian Psychology, ISSN 2348-5396 (e)| ISSN: 2349-3429 (p) | 61 
steps involved in it are learning to identify excessive tension in certain muscles and learning to reduce and if possible, eliminate that tension. This procedure is repeated with various muscle groups of the body.

\section{Cognitive restructuring}

The primary aim of cognitive restructuring understands the errors in individual thinking, help him to modify them and replace them with more adaptive thoughts, since these thoughts were playing a major role in causing as well as maintaining the symptoms

\section{THERAPY PROCESS}

First session: The patient was reported along with the uncle. Intake interview was conducted. Patient was psycho-educated about the nature and treatment of the problem and explained the process of therapy. Psycho-education was mainly aimed at educating client that how his symptoms were started, the triggering factors and how it is maintained. Patient is taught about the nature and function of anxiety and its nervous system correlates. The education provides patient with a model of anxiety that emphasize the interaction between the mind and body and provides a rational and framework for the skills to be taught during treatment. A three dimensional model is utilized, in which dimensions of anxiety are grouped in to physical, cognitive and behavioural categories. The physical component includes bodily changes and their associated somatic sensations. The cognitive component includes thoughts, images and impulses that accompany anxiety. The behavioural component contains behaviours that associated with anxiety (e.g. avoiding or escaping from the situation). These three components are described as interacting with each other, often with the result that anxiety is heightened. The therapist then explains that the goal of treatment is to learn skills for controlling each of the three components of anxiety.

Supportive psychotherapy was given to the client because the client was feeling helpless and sad. Therapy was carried out to make the patient develop self-confidence. The platform was created for the verbalization of patient's strong unexpressed emotion to bring considerable relief to the patient and leading to the reduction of tension and anxiety.

The client was given understanding regarding the importance of relaxation for her problem and also explained the rationale for the same. Jacobson Progressive Muscle Relaxation was introduced in this session. Before this session therapist demonstrate to the patient how to tense and relax various groups of muscles. He was asked to come consecutively for five days of relaxation training.

Second session: Previous session was reviewed and clarifies the doubts of the patient. JPMR was continued for the 45 minutes. After the session he reported that he is feeling fresh following relaxation training. 
Third session: Previous session was reviewed. JPMR has been practiced. He reported that while tensing up the muscle, his heart beat increased, but later he felt better and relaxed. The patient was asked to practice JPMR at home in a calm environment, not in full stomach, if possible morning and evening.

Fourth session: JPMR training was continued and the patient was asked to not avoid the anxious situation and make her understand avoidance itself become a problem. He was asked to develop confidence by being internally bold. According to the patient the breathing problem while speaking with was reduced compare to earlier.

Fifth session: First 45 minutes were spent for Jacobson's Progressive Muscle Relaxation. During this session patient practiced relaxation alone and the therapist observed and gave corrections for the mistakes he has done during the relaxation and advised the patient to practice relaxation on daily basis at home.

Sixth session: The patient was reported along with the uncle. The patient and his uncle reported overall improvement in her condition. Previous session is reviewed. Cognitive restructuring was done. Regarding the problem related to her preoccupation about the financial matters. Therapist told not to avoids any anxious situation, because the avoidance itself becomes a problem.

Seventh session: Patient was reviewed after 20 days. He reported that he is maintaining well in army. He reported that he could feel significant difference in his condition. He reported that his headache is not reduced that much but all the symptoms are reduced. So thermal training technique was taught (he was told to put her fingers in warm water, keep his eyes closed and relax for 15 minutes). He reported that now he has less anxiety.

\section{CONCLUSION AND OUTCOME}

Seven session were held with the patient. Later the patient reported that there is a significant improvement in his condition. He reported that therapy was not helped him to reduce his symptoms but also helped to improve his self- confidence and also helped to reduce problems in interpersonal relationship in army area. Therapy helped him to identify his thinking errors and modify it to the extent that he can understand the situation in a more realistic way. Similar study conducted by Behar \& Borkovec (2005) which suggests that some specific treatment components for generalized anxiety disorder have been developed based on the central tenets of the cognitive behavioural techniques include: (a) self-monitoring of external situations, thoughts, feelings, physiological reactions, and behaviours; (b) relaxation techniques such as progressive muscle relaxation, diaphragmatic breathing, and pleasant relaxing imagery; (c) self-control desensitization, which entails the use of methods (e.g., imaginal rehearsal) to facilitate the acquisition of habitual coping responses; (d) gradual stimulus control achieved by establishing a specific time and place for worrying; (e) cognitive restructuring aimed at increasing clients' flexibility in thinking and access to multiple, flexible perspectives; (f) worry outcome monitoring in which clients keep regular diary entries in order to monitor specific worries, their feared outcomes, and the actual outcomes of those worries; (g) the promotion of present-moment focus of attention, and (h) expectancy-free living. A wide range of behavioural and problem solving 
psychological approaches can be effective for patients with anxiety disorders (Dowell et al.2009). Cognitive behavioural therapy (CBT) is the most widely used and may be useful for some patients with GAD (CPA, 2006; Kavan et al. 2009; NPS News, 2009).

\section{FUTURE PLAN}

Regular monthly follow ups were suggested. Patient has a problem in decision making. Made him to be independent in decision making is one of the future targets. Patient lacks selfconfidence and communication skills. So social skill training is important for dealing with it.

\section{Acknowledgments}

The author appreciates all those who participated in the study and helped to facilitate the research process.

Conflict of Interests: The author declared no conflict of interests.

\section{REFERENCES}

American Psychiatric Association.(1994). Diagnostic and Statistical Manual of Mental Disorders. Fourth Edition. Washington, DC: American Psychiatric Press, 432-436.

Baldwin DS, Anderson IM, Nutt DJ. (2005). Evidence based guidelines for the pharmacological treatment of anxiety disorders: recommendations from the British Association for Psychopharmacology. J Psychopharmacol, 19(6), 567-96.

Behar, E., \& Borkovec, T. D. (2005). The nature and treatment of generalized anxiety disorder. In: B. O. Rothbaum (Ed.), The nature and treatment of pathological anxiety: essays in honor of Edna B. Foa (pp. 181-196). New York: Guilford

Canadian Psychiatric Association. Management of Anxiety Disorders. Can J Psychiatry 2006;51(Suppl 2).

Christensen H, Griffiths KM, Jorm AF. (2004).Delivering interventions for depression by using the internet: randomised controlled trial. BMJ, 328 (7434), 265.

Ciechanowski P, Katon W. Overview of generalised anxiety disorder. UpToDate 2009. Available from: www.uptodate.com (Accessed November, 2009).

Dowell A, Garrett S, Collings S. (2009). Evaluation of the Primary Mental Health Initiatives: Summary report 2008. Wellington: University of Otago and Ministry of Health.

Kavan MG, Elsasser GN, Barone EJ. (2009). Generalised anxiety disorder: Practical assessment and management. Am Fam Physician, 79(9), 785-91.

National Prescribing Service Limited. (2009).Which treatment for what anxiety disorder? NPS News, 65. Available from: www.nps. org.au (Accessed November, 2009).

Tyrer, P., \& Baldwin, D. (2006). Generalised anxiety disorder. Lancet, 368, 2156-2166.

Wittchen HU, Hoyer J. (2001). Generalized anxiety disorder: nature and course. J Clin Psychiatry, 62(11), 15-19. 
Application of Psycho-Social Management in Generalized Anxiety Disorder: A Clinical Case Perspective

Yonkers, K. A., Dyck, I. R., Warshaw, M., \& Keller, M. B. (2000). Factors predicting the course of generalised anxiety disorder. British Journal of Psychiatry, 176, 544-549.

How to cite this article: Aggarwal S, Srivastava P (2017), Application of Psycho-Social Management in Generalized Anxiety Disorder: A Clinical Case Perspective, International

Journal of Indian Psychology, Volume 4, Issue 2, No. 87, ISSN:2348-5396 (e), ISSN:2349-3429 (p), DIP:18.01.048/20170402, ISBN:978-1-365-71287-6 